\title{
Virtues and Oppression: A Complicated Relationship
}

\author{
MARILYN FRIEDMAN
}

This paper raises some minor questions about Lisa Tessman's book, Burdened Virtues. Friedman's questions pertain, among other things, to the adequacy of a virtue ethical focus on character, the apparent implication of virtue ethics that oppressors suffer damaged characters and are not any better off than the oppressed, the importance of whether privileged persons may have earned their privileges, and the oppositional anger that movement feminists sometimes direct against each other.

Lisa Tessman's book, Burdened Virtues, is a unique contribution to contemporary virtue theory. Traditional virtue ethics sadly ignores the conditions of oppression that impede the flourishing of many people. Tessman rectifies this omission by exploring a variety of ways in which oppression damages people morally by promoting harmful character traits in them or, at any rate, complex traits that are harmful in some ways even if they are also beneficial in other ways and necessary for resisting oppression. Tessman's book examines these problems in the context of virtue theory with its emphasis on character and flourishing. I have only minor comments and questions about Tessman's otherwise excellent book.

First comment: Tessman suggests that "action-centered ethics" are too limited for the liberatory project of self-transformation. She thinks that virtue ethics with its focus on character is better suited to exploring these concerns because the issue is primarily about the agent's character and not about the (right) actions she should perform (20). I question, however, whether a virtue can really be specified independently of the right actions that exemplify it. A virtue is a complex disposition that includes tendencies to behave in characteristic ways under various conditions. To know that a character trait is a virtue, 
one has to know that the behaviors it tends to promote are the right things to do under the circumstances in which they occur.

Tessman argues that "an oppressed and morally damaged self" may not be able to perform the right action or may do it with "psychic pain." The oppressed person's desires, which do not yet cohere with her principles, may conflict with her principled judgment about what she should do. Feminist action-centered ethics do not consider how one is to overcome this "psychic pain" (20-22).

Tessman raises an important problem. However, it does not show that actioncentered ethics is wrong; only that it is incomplete as a guide for motivation. I suggest that in order for someone to know which of her character traits need to be transformed, part of what she needs to know is what the right thing to do is under the various sorts of situations she faces. By trying to do the right thing, she finds out whether her desires, emotions, attitudes, and so forth motivate her to do the right thing or whether they lead her to be ambivalent or reluctant about doing the right thing.

Tessman suggests that the feminist politics of personal transformation has tended to assume falsely that the will to change one's character can be put into practice easily, perhaps with just a bit of feminist conscious-raising (24). However, an action-centered ethics does not have to make this assumption. It does not have to ignore the fact that some people resist doing the right thing because their characters are damaged by oppression (23). ${ }^{1}$

Tessman is right to say that feminist ethics should consider the issue of human flourishing, something distinctive of Aristotelian virtue theory, and should consider how personal character traits, emotions, desires, and so on may impede one's motivations and tendencies to do what is right and to flourish (23). An action-centered ethics is incomplete as an account of all morally relevant concerns if it ignores the question of what makes for a good human life and the question of how to motivate ourselves to act rightly. At the same time, however, a character-centered virtue ethics is also incomplete without an account of right action. Action-centered ethics and character-centered ethics should supplement each other; they do not have to be competitors.

Second comment: Tessman discusses the old Socratic idea that being just and having virtues are necessary conditions for flourishing. If this is right, and if privileged persons do have moral flaws, the Socratic view would entail that they cannot flourish (53-54). Tessman doubts that privileged persons are morally good given that their privileges result from "unjust social positionings" such as male dominance, and they probably don't retain their privileges unless they have some vices, at least those of "culpable passive acceptance." Tessman calls these traits the "ordinary vices of domination" (54). Despite having such vices, many privileged persons are widely regarded as living a good life. Yet virtue theorists, at least the classical ones, try to show that people with vices do not live good lives. Tessman raises several perceptive questions about these issues. 
Tessman notices that there is a tension between, on the one hand, virtue theories that hold that those without virtue do not flourish, and, on the other hand, theories of oppression (56). The tension arises because if the oppressors do not flourish either, "then the claim that the oppressed are especially harmed by being morally damaged loses some of its force" (57). To be sure, the oppressed face unfavorable external conditions that members of dominant groups do not face. But virtue ethics combined with theories of oppression seems to entail that both oppressors and oppressed suffer in their characters and well-being under oppression, so that the oppressed are no worse off than the oppressors in these respects (57). This conclusion would somewhat undermine theories of oppression.

Tessman tries to resolve the difficulty of thinking that the oppressed are no worse off than the oppressors. She turns to a distinction between self-regarding virtues and other-regarding virtues that has become prominent among virtue theorists today (62). This distinction suggests what Tessman calls a "neat solution" to the problem of explaining how oppression is worse for the oppressed than it is for the oppressors: "the ordinary vices of domination are all failings of other-regarding virtues." Privileged persons fail to treat others with justice, compassion, and so on. At the same time, the moral damage suffered by oppressed persons is "damage to their capacities to be sufficiently self-regarding" (63).

The "neat solution" consists of two main premises: (A) privileged persons primarily have self-regarding virtues but not other-regarding virtues while oppressed persons primarily have other-regarding virtues but not self-regarding virtues; and (B) only the lack of self-regarding virtues interferes with flourishing. On this account, oppressors could still flourish through self-regarding virtues even while treating others immorally, and oppressed people could fail to flourish even though they treat others virtuously (64).

The first premise encompasses four claims: (A1) oppressed persons tend to lack self-regarding traits; (A2) privileged persons tend to have self-regarding traits; (A3) oppressed persons tend to have other-regarding traits; and (A4) privileged persons tend to lack other-regarding traits (67). Tessman agrees with claim A1 but disputes the other three.

She disputes claim A2, that dominant persons have self-regarding traits, by suggesting that privileged persons might not develop self-regarding traits such as habits of hard work or courage. I wonder whether Tessman's generalization relies on a stereotype of wealthy people as performing no labor and being "protected throughout life" (67). There are, to be sure, people who grow up on trust funds, who never hold down a serious job or have to exert themselves in the face of danger. However, there are also wealthy people who grow up as overachievers, work hard their whole lives, and show courage in the face of dangerous conditions. ${ }^{2}$ These are empirical matters and we should base our generalizations on empirical evidence. 
Also, Tessman's challenge to $\mathrm{A} 2$ involves a virtue switch. When discussing the self-regarding virtues of the oppressed, she focuses on virtues such as selfesteem. However, when questioning the self-regarding virtues of privileged persons, she switches to courage and work habits. What about the self-esteem of privileged persons? Both groups should be assessed in terms of the same virtues if we are to make a meaningful comparison.

Tessman challenges premise A 4 by arguing that dominant persons do acquire other-regarding traits. They can become compassionate and generous, for example. Granted, these traits are usually exercised selectively toward members of their own race or class, but within those confines, the traits are still genuine virtues.

However, Tessman also suggests both that the caring and nurturing of women in dominant groups are usually limited to family members and that this limitation helps maintain race and class privilege (68). Tangentially, I suggest that there are some important exceptions to this generalization. There are crossracial and cross-class families. Some of these families come about by adoption. Given the limited access to abortion in this country today, poor women and girls, many of them in minority racial groups, are usually the ones who are forced to carry unwanted pregnancies to term and then give up their babies for adoption. Usually, when discussing women's traditional nurturing, we forget about families by adoption, which often cross class boundaries and sometimes cross race boundaries as well. Thus the care labors of dominant group women may well extend across class and race lines to some extent.

Back to the main point of this section. Tessman, to her further credit, raises suspicions about premise $\mathrm{A} 3$ of the "neat" solution, the claim that the oppressed tend to have other-regarding virtues. Tessman considers that the supposed virtues, such as an emphasis on justice and equality, may stem from a Nietzschean resentment against dominant persons and may mask what is actually an attempt to injure the dominant. Thus, overall, Tessman argues, there is no clear alignment of other-regarding virtues with oppressed persons and self-regarding virtues with privileged persons (69). ${ }^{3}$

With the qualifications I just mentioned, I tend overall to agree with Tessman's rejection of premise A of the "neat" solution. Tessman also challenges premise B of the "neat" solution (the claim that only the lack of self-regarding virtues interferes with flourishing) by arguing that other-regarding virtues are "ultimately beneficial for the agent" (72). ${ }^{4}$ We thus seem to be left with the tentative conclusion that oppression does undermine some of the virtues for both oppressed and privileged persons (different ones in each case), and no basis for thinking that oppressed persons are harmed more profoundly in these moral ways than are dominant persons (73).

Still searching for an account of how oppressed persons suffer greater moral damage than privileged persons, Tessman explores Aristotle's insistence that 
human well being requires being part of a community whose flourishing one helps promote by doing good for other members of it (74). Aristotle believed that a community can be successful even if it is exclusivist and only some of its members are flourishing.

Tessman carefully challenges this idea. Unfortunately, she thinks the old slogan "no one is free while others are oppressed" is false. I agree with her. As Tessman explains it, people who are not oppressed can find happiness or freedom "by simply not noticing the others" (76). All they need is to be part of a flourishing interdependent community of some sort, exclusivist or not.

Tessman's own resolution of this problem is to distinguish flourishing from subjectively felt happiness. ${ }^{5}$ Tessman maintains that both self-regarding virtues and other-regarding virtues are required for flourishing. In this respect, she agrees with Aristotle. However, Tessman and Aristotle soon part company. For Aristotle, the "others" to whom a virtuous person must pay regard constituted a narrow and exclusionary social group of freeborn privileged men. ${ }^{6}$ Because of these exclusionary possibilities, privileged people, for Aristotle, can be otherregarding yet show no moral concern whatsoever to those whose labors support their privileges. For Tessman, this result shows that self-regarding virtues and other-regarding virtues, abstractly speaking, are still not sufficient for flourishing. In her view, virtuous behavior does not constitute flourishing unless it is morally good, and morally good flourishing requires that one simultaneously pursue "the well-being of those whose very lack of well-being may have been a condition of my privileges" (76, emphasis added). I think this is the right approach to the issue of who can flourish. Yet it raises some questions.

How are we to understand the wording, "those whose very lack of well-being may have been a condition of my privileges"? We need a fuller account from Tessman of what sorts of relationships are grounds for the requirement to have moral concern for the well being of particular people who are oppressed. Does the requirement hold only when someone's oppression is in fact the condition of my privilege? Am I off the hook if someone is oppressed but in actual fact, whether I know it or not, their oppression is not a condition of my privilege?

Third comment: To convince an audience beyond those who are already concerned about social justice issues, Tessman should not simply take it for granted that anyone who happens to be privileged did not earn her privileges and is necessarily treating unprivileged persons badly. Arguments are needed to establish these points. There are two possibilities that might be conjointly true. First, privileged persons may have gained or maintained their privileges by acting wrongly as individuals toward unprivileged persons. Second, privileged persons may have gained or maintained their privileges by benefiting from social institutions that embody injustices. Although privileged persons might not have done anything individually wrong to gain their privileges in this latter case, they might still have responsibilities to rectify the injustices that provided them with 
unearned privileges. Tessman's concept of the "ordinary vices of domination" is relevant to this second issue. However, without an account of the source of unjust social privileges and the specific responsibilities of privileged persons to rectify those wrongs, we can't make any assumptions about the overall moral characters of privileged people.

In addition, Tessman's theory of personal responsibility seems to hold that oppressed persons do not bear individual responsibility for their circumstances but privileged persons do bear individual responsibility for the circumstances of oppressed persons (through their intentionally unjust or cruel acts, or their failures to change unjust institutions). It would help Tessman's argument to have a social theory to explain this difference in individual responsibility and to show that it does not patronize oppressed persons by underestimating their moral agency.

Fourth comment: Tessman argues that people should cultivate a substantial degree of sensitivity to the conditions of others, although not so much as to be overwhelmed by anxiety ( 80$)$. Given the outrages that happen around the world on a daily basis, even a fully responsive person can never do enough to stop it (83). There is a limitless need to prevent preventable unjust suffering and no one is able to make substantial headway against all of it. Thus, attunement to the sufferings of others seems to involve unlimited pain (92). This is a problem for Aristotelian virtue theory, which holds that a virtuous person feels pleasure at the thought of acting rightly; part of what it is to be virtuous is to feel good about doing the right thing. Yet attending to the suffering of others seems to require a substantial amount of pain (93).

A related problem arises in the virtue theoretic requirement that one is supposed to feel good about doing good for others. Tessman suggests that there is something "repugnant" about feeling good about the fact that one relieves someone's suffering. The occasion for one's moral goodness is the suffering of another person. Without that suffering, one would not have had the opportunity to help them (93n18). Perhaps the most vittuous person is in fact not the one who simply feels good about relieving someone's suffering but rather the one who relieves the suffering while also feeling bad that there was any suffering to relieve. ${ }^{?}$

Fifth comment: Resisting oppression, which is necessary if the oppressed are ever to flourish, may require traits that are burdened in ways that interfere with the flourishing of those who engage in political struggle. Tessman explores this possibility, using the example of complications that may tarnish oppositional anger $(107-9,119)$. For example, anger can be directed against the wrong target -other oppressed persons instead of privileged persons (120-22). This phenomenon is easy to understand. Powerful people can be dangerous to confront directly, so it is tempting to redirect anger toward a safer target, such as another oppressed person. Tessman observes how this redirection is facilitated 
by the way multiple oppressions crosscut each other. Some people are both privileged and subordinated-white women, for example-so in some ways they can be appropriate targets of political anger.

It is easier to get angry at, or mock, the "white suburban middle-class matron" who hires one cleaning woman from a minority group than to get angry at or mock her husband who exploits a hundred minority workers in his factory. A white woman is usually easier to attack than her husband because she generally has less power than he does to engage in self-defense or fight back. Tessman's comments reminded me that it sometimes seems as if almost every oppression-fighting group gets angry at feminists. Movement feminists have been accused of being privileged in just about every possible way other than gender: as white, middle-class, Western, heterosexual, ablest-you name it-and of utilizing those privileges. However, oppression-fighting anger seems wasted if it is directed at targets with relatively little power to rectify the injustice in question. Being "privileged" is not the same thing as being "dominant."

Feminist activists sometimes defend their anger at other feminists by saying that it stems from a sense of having been betrayed (135). The idea is that if a white, heterosexual, middle-class man says or does something harmful to women or any other oppressed group, well, no one expects better of him. However, if a woman in the group does something that seems covertly sexist, racist, or heterosexist, she has betrayed the group because she is in the group and should have known better.

I see two problems with this reaction. First, angry critics usually show no tolerance whatsoever for mistakes by other group members. They often seem to have no principle of charity, and seem unable or unwilling to assume goodwill on the parts of others in the group who are having a hard time overcoming lingering ignorance or bias. Second, through the use of criticism, angry critics de facto become dominant within their subordinate groups, something that subverts the antihierarchical values of their groups.

Sixth comment: And related to the previous point, Tessman discusses the virtue of loyalty to a politically resistant community, a virtue that leads one to be open to political criticism by community members. This loyalty is valuable in enabling one to break away from dominant societal values and reorient one's self. However, Tessman rightly worries about the complications of such loyalty (128-29). I would add to her concerns that excessive political criticism by a valued community can be devastating to one's self-esteem. The power of criticism is a power that the dominant members within politically resistant groups can wield over nondominant members of their own groups. Even a rhetoric of equality and opposition to hierarchy and privilege may not eliminate the tendency of some people with dominant personalities to control the norms and values of their oppressed communities. 
Despite all these burdens of the virtues of resisting oppression, Tessman does not suggest that people give up resisting oppression. Giving up resistance, in her view, is definitely worse than combating oppression, even with all the burdens of the latter. The real issue, she writes, "is not whether to resist but how to resist" (131). Tessman's book is an astute and discerning call for full understanding of the regrettable aspects of the virtues one must take on if one is to respond morally to oppression.

\section{Notes}

1. Tessman suggests that this omission is a "problem of an action-centered approach" (23). My point is that it does not have to be so.

2. Privileged people sometimes face dangerous conditions voluntarily and for the excitement and challenge of it, for example, an icy ski slope. The fact that such conditions are faced voluntarily does not mean that facing them requires no courage. Also, privileged people are not immune from being confronted with dangerous conditions they do not choose to cope with but must still do so, for example, rape or a life-threatening illness.

3. I would also add that I don't think oppressed persons are less partial in their other-regarding virtues than privileged persons; both sorts of persons, I believe, tend to show virtuous concern selectively for the members of their own groups. Of course, the members of oppressed groups need selective concern more than do the members of privileged groups. But in the case of oppressed persons, selective concern may result in a tendency to care for the needs of one's own oppressed group only and to ignore other oppressed groups.

4. As I said earlier, I don't know of any virtue theorists who deny this.

5. I am grateful to Lisa Tessman for clarifying her position on these issues in private correspondence.

6. And the "one" in question would presumably also be one of those freeborn privileged men.

7. Tessman also discusses "traits whose status as virtues is murky in part because their value actually depends upon the presence of terrible conditions (95)." However, she has a different concern in mind here. If the virtue of sensitivity to the suffering of others is inherently painful, then the connection of this virtue to flourishing seems to be broken. Standard virtue theory has it that genuine virtue feels unqualifiedly good. Tessman has thus uncovered another puzzle in standard virtue theory. 